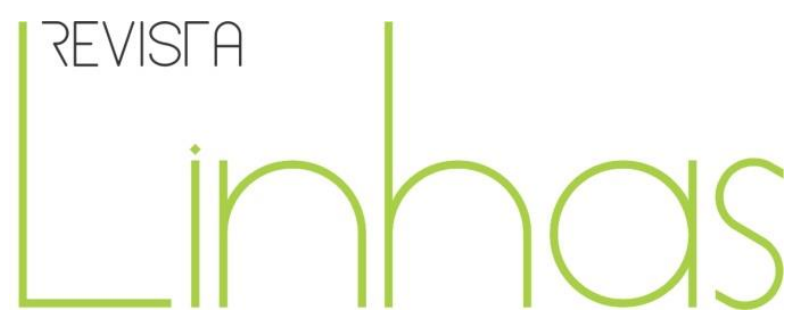

\title{
Arte, educação musical e a formação do pedagogo: notas sobre uma experiência
}

\section{Resumo}

O presente texto busca resgatar um percurso de ensino, pesquisa e extensão realizado pelo Grupo de Estudos em Cultura, Trabalho e Educação a partir de uma síntese dos trabalhos publicados em anais do Congresso Nacional da Associação Brasileira de Educação Musical (ABEM), fruto de nossas vivências, que mostram como vimos refletindo sobre a nossa experiência de pensar a arte - e a música em particular - como uma forma de conhecimento, de expressão e de pensamento fundamental para a formação e o trabalho do pedagogo. Esses trabalhos estão inseridos no contexto da formação inicial e continuada de professores não especialistas na área da música a partir do projeto de pesquisa Arte, educação musical e a formação do pedagogo. Para além da compreensão de que a música potencializa aspectos sensíveis da condição humana - o que por si só justificaria a necessidade da sua presença na educação básica e na formação do pedagogo - esse trabalho nos proporcionou a compreensão de que precisamos conhecer in loco a realidade das escolas se quisermos efetivamente contribuir com as suas demandas, não apenas no sentido de atendê-las, mas também no de discuti-las. O texto reflete uma busca incessante pela compreensão do lugar da música no processo de formação da criança no espaço escolar e, como consequência, da formação musical desejável para o professorpedagogo.

Palavras-chave: Educação Musical. Arte. Formação de Professores. Educação Básica. Pedagogia.

\section{Para citar este artigo:}

REQUIÃO, Luciana. Arte, educação musical e a formação do pedagogo: notas sobre uma experiência.

Revista Linhas. Florianópolis, v. 20, n. 42, p. 102-124, jan./abr. 2019. 


\title{
Art, music education and teacher training: notes on an experience
}

\begin{abstract}
This text is aimed at rescuing the way the Grupo de Estudos em Cultura, Trabalho e Educação (Study Group in Culture, Work and Education) promotes teaching, research and education, based on a summary of the papers published in the proceedings of the National Conference of the Brazilian Association of Music Education (ABEM). These works are the result of our experiences and show that we have been considering art - and especially music - to be a way of knowledge, expression and thought that is essential to teacher training and work. These works were written in the context of the initial and continuing education of teachers who are not experts in the field of music, and they are part of the research project Arte, educação musical e a formação do pedagogo (Art, music education and teacher training). In addition to understanding that music enhances the aspects sensitive to human condition - which would justify the presence of music in basic education and teacher training - this work allowed us to understand that we need to know the reality of the schools in loco to meet and discuss their demands, if we in fact want to contribute to them. This text shows a constant search for the understanding of the place of music in the process of children education at school and, as a consequence, mentions the type of music education desirable for teacher training.
\end{abstract}

Keywords: Music Education. Art. Teacher Training. Basic Education. Pedagogy. 


\section{Apresentação}

No ano de 2009, o recém-criado Instituto de Educação de Angra dos Reis (IEAR), da Universidade Federal Fluminense (UFF), era constituído por apenas um curso de Pedagogia, já existente na região desde 1992, oriundo de um convênio entre a prefeitura de Angra dos Reis e a Faculdade de Educação da UFF, localizada no campus do Gragoatá na cidade de Niterói. O curso tinha uma estrutura curricular bastante diferenciada do ciclo semestral que é habitual nas universidades brasileiras, composto por núcleos de estudos que duravam cerca de dez semanas cada. Nessa proposta não haviam disciplinas voltadas especificamente para o ensino das artes. ${ }^{1}$

Curiosamente, a ausência das artes na formação de professores-pedagogos não era uma particularidade desse currículo. Apesar de constar em documentos oficiais - o Referencial curricular nacional para a educação infantil (BRASIL, 1998) e os Parâmetros Curriculares Nacionais: arte (BRASIL, 1997), entre outros - que se referem às artes como sendo uma parte fundamental do desenvolvimento humano, a literatura existente mostra que ainda são poucos os cursos de Pedagogia que se preocupam com a questão. Mesmo quando há qualquer movimento nessa direção, "a preparação artística, em geral, e a preparação musical, em particular, têm sido abordadas de forma superficial e insuficiente pelos cursos formadores desses profissionais" (FIGUEIREDO, 2004, p. 56). Em um trabalho mais recente, Bellochio, Weber e Souza. (2017, p. 218) encontraram um resultado análogo ao de Figueiredo, ao revisar pesquisas realizadas nos últimos anos que apontam para "a ainda insuficiente, quando não nula, formação musical nos cursos de Pedagogia". No estado do Rio de Janeiro, por exemplo, dos dezenove cursos presenciais ofertados por instituições públicas apenas um parece dar destaque à música como um conteúdo curricular obrigatório. ${ }^{2}$

Em 2010, os docentes lotados no Departamento de Educação do IEAR, todos recém-contratados, realizaram uma primeira reforma curricular que, tendo como referência o currículo do curso de Pedagogia da Faculdade de Educação da UFF,

\footnotetext{
1 Segundo documento disponível em: <http://www.proac.uff.br/files/Pedagogia\%2oAngradosReis.pdf>. Acesso em: 01 ago. 2017.

2 Informações obtidas em: <http://emec.mec.gov.br/>. Acesso em: 03 jun. 2018. Os currículos foram consultados nos sites das respectivas instituições. Por meio dessa consulta, encontramos apenas um curso que possui a música como uma disciplina curricular obrigatória. Trata-se do curso de Pedagogia do Instituto de Educação Musical de Angra dos Reis (IEAR/UFF).
} 
contemplou a disciplina Arte e Educação como obrigatória na integralização dos créditos necessários para a conclusão.

Na ocasião, conjuntamente com a professora Silmara Lídia Marton e um grupo de estudantes daquele curso, formamos um grupo de pesquisa que buscava conhecer e compreender como se dava a prática musical nas escolas públicas da região. ${ }^{3}$ Esse primeiro movimento se deu instigado pela promulgação da Lei 11.769, em agosto de 2008, que alterava o artigo $26^{\circ}$ da Lei 9.394, que estabelece as diretrizes e bases da educação nacional (BRASIL, 1996) ao definir que “a música deverá ser um conteúdo obrigatório, mas não exclusivo, do componente curricular de que trata o § 20 deste artigo" (BRASIL, 2008), a saber: o ensino da arte. Vale notar que, em 2016, tivemos novamente uma alteração na LDB, Lei $n^{\circ} 9.394 / 96$, com a Lei $n^{\circ} 13.278$, de 2 de maio, na qual tivemos as quatro linguagens - as artes visuais, a dança, a música e o teatro - previstas como componentes curriculares obrigatórios no ensino da arte.

Na área da música, há uma extensa discussão sobre a existência prevista em lei de um componente curricular que abarque o conteúdo de quatro linguagens artísticas. Essa discussão se dá em torno da polivalência requerida ao professor e, consequentemente, da formação de um profissional polivalente nos cursos de licenciatura em Educação Artística, coisa que já ocorria por conta da Lei 5.692, de 11 de agosto de 1971. No contexto dessa última, de acordo com Fonterrada (2008), ao assumir a ideia de uma "educação artística”,

o governo estava contribuindo para o enfraquecimento e quase total aniquilamento do ensino de música; os cursos superiores de educação artística surgiram em 1974, um pouco depois da promulgação da lei, e tinha caráter polivalente. Hoje, passados tantos anos, ainda se sentem os efeitos dessa lei, não obstante os esforços de muitos educadores musicais para fortalecer a área. (FONTERRADA, 2008, p. 218)

A autora observa um avanço, após a Lei 9.394, quando a arte de atividade passa a ter o status de uma disciplina: "um dos mais importantes ganhos decorrentes da promulgação da nova lei talvez seja o fato de a arte ter passado a ser oficialmente considerada um campo de conhecimento" (FONTERRADA, 2008, p. 229). Fonterrada

\footnotetext{
${ }^{3}$ A partir desse encontro foi formado o Grupo de Estudos em Cultura, Trabalho e Educação - GECULTE. Ver em <www.culturatrabalhoedu.uff.br $>$.
} 
(2008, p. 235) entende que, com a especificação de cada linguagem descrita nos PCN, "há uma clara tendência a tratar as diferentes linguagens artísticas em suas especificidades". De outro lado, Santos (2012) observa que mesmo a Lei 9.394 "deixou uma vaguidade que se tentou preencher com os Parâmetros Curriculares Nacionais, onde as modalidades Artes Visuais, Dança, Teatro e Música estão descritas separadamente” (s. p.).

O fato é que hoje, com uma única disciplina - Artes - composta por quatro linguagens artísticas inerentes, ainda estamos diante de uma situação pouco satisfatória. Embora as licenciaturas plenas na área da educação artística prevejam uma única habilitação específica para o professor de artes (artes visuais, dança, música ou teatro), não é comum observarmos a presença dos quatro perfis profissionais no ambiente escolar, o que seria de se esperar. Os cursos de Pedagogia, de forma geral, também não atendem à necessidade de formação na área da arte dos futuros professores regentes de turma, sendo esta, apesar da possibilidade da presença do professor especialista, também uma área de conhecimento do professor-pedagogo, conforme mostra Figueiredo:

O curso de Pedagogia deve incluir as artes, de acordo com as diretrizes curriculares específicas deste curso (BRASIL, 2006). Nestas diretrizes estão incluídas as atribuições do pedagogo: "ensinar Língua Portuguesa, Matemática, Ciências, História, Geografia, Artes, Educação Física, de forma interdisciplinar e adequada às diferentes fases do desenvolvimento humano". (FIGUEIREDO, 2017, p. 84)

Nesse contexto, nos coube a difícil tarefa de elaborar uma ementa para a disciplina Arte e Educação, com apenas 60 horas de duração, que pudesse colaborar com a formação de um professor-pedagogo capaz de articular conhecimentos e experiências fundamentais para o desenvolvimento humano, levando em conta um período tão especial de nossa formação como o que é vivido na educação infantil e nas séries iniciais do ensino fundamental.

Nessa busca, sintetizamos todas as nossas aspirações na descrição contida na ementa da disciplina:

O conceito de arte. Fundamentos da arte-educação. A arte como instrumento favorecedor da aprendizagem. Arte e criatividade. A necessidade da arte (a origem e a função da arte). As múltiplas 
linguagens artísticas $\mathrm{e}$ as suas relações com a produção do conhecimento. A arte nos PCN. Vivências educativas através da arteeducação. A pertinência da arte na educação. Perspectivas do ensino da arte em relação à formação do pedagogo. Planejamento e avaliação em artes. Prática de ensino. ${ }^{4}$

Porém, na prática, a disciplina tornou-se análoga às disciplinas de fundamentos do curso de pedagogia do IEAR, de caráter mais teórico, já que, como professora graduada em educação artística com habilitação em música, eu não poderia propor práticas de ensino-aprendizagem específicas de outras linguagens artísticas. Para tratar das especificidades da linguagem musical foi incluída, a partir da reforma curricular do curso de Pedagogia realizada em 2015, a disciplina Educação Musical: Conteúdo e Método como um componente obrigatório e a disciplina a distância Educação Musical como optativa. Essa primeira, a partir de 2018, passou a ser intitulada Música e Educação. ${ }^{5}$

Nesses últimos oito anos, estivemos envolvidos em ações de ensino, de pesquisa e de extensão que nos permitiram avaliar continuamente o significado e a importância da arte, e, em particular, da música na formação do pedagogo e, consequentemente, na escola e em outros espaços de atuação desse profissional. ${ }^{6}$ Além das já mencionadas disciplinas, desenvolvemos nesse período quatro projetos de pesquisa ${ }^{7}$ e seis cursos de extensão. ${ }^{8}$ Realizamos ainda quatro edições do seminário Música e Educação do IEAR,

\footnotetext{
${ }^{4}$ Documento não publicado.

${ }^{5}$ Vale notar que a inclusão da referida disciplina no currículo do curso não foi isenta de disputas e de ações que caracterizassem a necessidade desse conteúdo na formação do pedagogo. Esse tema será tratado adiante.

${ }^{6}$ Nesse caminho, contei com as valiosas colaborações da professora Silmara Lídia Marton, que dividiu comigo as tarefas iniciais de pesquisa e de extensão e, ainda hoje, colabora com as referidas disciplinas, da professora Dagmar de Mello e Silva, com quem pude vivenciar uma rica experiência ao lado da Cia das Artes Severinas, grupo formado junto a estudantes do curso de pedagogia do IEAR, e da professora Adriana Manzolillo Sanseverino, pedagoga e técnica em assuntos educacionais do IEAR, com quem venho dividindo nos últimos anos os meus interesses e questões de pesquisa junto ao Grupo de Estudos em Cultura, Trabalho e Educação. Sobre as atividades do grupo, ver: <http://projetomusica2011.blogspot.com.br/>.

7 São eles: Implementação da Lei 11.769: construção de uma proposta de formação inicial e continuada para professores da rede pública da Costa Verde Sul Fluminense na área da educação musical (2011-2012); Formação inicial para professores da rede pública da Costa Verde Sul Fluminense na área da educação musical: uma proposta de material didático para auxílio à implementação da Lei 11.769/08 (2012-2013); Formação inicial para professores da rede pública da Costa Verde Sul Fluminense na área da educação musical: avaliando e consolidando um percurso de pesquisa e extensão (2014-2015); e Arte, educação musical e a formação do pedagogo: aplicação e análise de materiais didáticos (2016-atual). Os três primeiros tiveram apoio financeiro da FAPERJ.

${ }^{8}$ São eles: Iniciação em educação musical e escuta sensível (2010); Cia das artes Severina (2011-2014); Formação inicial e continuada em música e educação (2012-2013); Oficinas de música (2012-2014); Sons e
} 


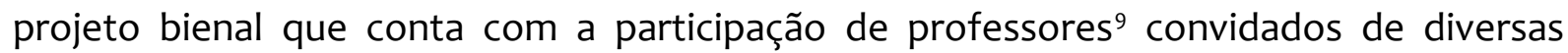
localidades do país.

O objetivo do presente artigo é resgatar esse percurso a partir de uma síntese dos trabalhos publicados em anais do Congresso Nacional da Associação Brasileira de Educação Musical (ABEM), fruto de nossa experiência, que mostram como vimos refletindo sobre a arte - e a música em particular - como uma forma de conhecimento, de expressão e de pensamento fundamental para a formação e o trabalho do pedagogo. ${ }^{10}$ Esses trabalhos estão inseridos no contexto da formação inicial e continuada de professores não especialistas na área da música, a partir do projeto de pesquisa Arte, educação musical e a formação do pedagogo. É o que apresentaremos a seguir.

\section{Educação musical e escuta sensível: uma proposta de formação de professores}

Este artigo foi escrito por mim e pela professora Silmara Lídia Marton na ocasião do XX Congresso Nacional da Associação Brasileira de Educação Musical, realizado na cidade de Vitória/ES em novembro de 2011 (REQUIÃO; MARTON, 2011). Nele, buscamos mostrar os primeiros passos de uma experiência de formação na área da educação musical, no âmbito da formação de professores não especialistas em música, que, para além do atendimento à Lei 11769, pela via da articulação entre a escuta sensível e a educação musical, visou promover uma formação estética e mais integral dos alunos. 0 texto destacou como o intercâmbio ou a fusão de nossas diferentes trajetórias de

\footnotetext{
pulso: formação inicial em música e educação (2013-atual); e Violão para professores da educação infantil (2017).

9 Dentre outros profissionais, tivemos a oportunidade de contar com a presença e colaboração das professoras Regina Márcia Simão Santos, Silvia Sobreira, Inês Rocha e Cláudia Bellochio. Também não poderia deixar de mencionar aqui a fundamental participação dos estudantes de pedagogia junto aos projetos de pesquisa e extensão, dos professores da rede pública de Angra dos Reis, Mangaratiba e Paraty, das Secretarias de Educação dos respectivos municípios, do Conselho Municipal de Educação de Angra dos Reis, da direção, dos funcionários e das coordenadoras do curso de Pedagogia do IEAR, além das monitoras das disciplinas Arte e Educação, e Educação Musical: Conteúdo e Método que, a partir de 2015, foram contempladas no Edital de Monitoria da UFF por meio do projeto Arte, educação musical e a formação do pedagogo, que dá título ao presente texto. As monitoras do projeto, nesses três anos, foram as estudantes de pedagogia do IEAR Fernanda Luiza dos Santos (2015), Karine Ribeiro Rodrigues (2016) e Bianca da Silva Nóbrega (2017).

${ }^{10}$ Para conhecer a ABEM visite a página: <http://www.abemeducacaomusical.com.br/>.
} 
formação e de vida pôde complementarmente colaborar para os objetivos do curso. ${ }^{11}$ Buscamos ressaltar o ensino da música em seus aspectos estético e afetivo, considerados por nós como primordiais para a formação humana, em particular na chamada "escuta sensível”, noção apreendida dos trabalhos do educador e compositor Murray Schafer (2001).

Discutimos igualmente a importância do ensino da música no contexto escolar, tendo como referência as reflexões do musicólogo, compositor e educador Carlos Kater, que entende que o valor formador da música está em promover a

revitalização da sensibilidade e da curiosidade; possibilidade de alteração da consciência, centramento e intensificação da atenção (a que chamamos consciência); experimentação do sentimento de êxtase e contato com o sublime; suspensão da percepção cotidiana e utilitária; instauração de novas e mais originais modalidades de compreensão e de relacionamento com o mundo. (KATER apud SEKEFF, 2002, s.p.)

Partimos de um pressuposto básico de que educação envolve os atos de pensar e de sentir que, por sua vez, são condições necessárias para uma construção do conhecimento que respeite a multiplicidade de valores e visões de mundo presentes no universo cultural da contemporaneidade. Assim, partimos em defesa de uma "escuta sensível” que esteja atenta também à "paisagem sonora” do mundo que nos rodeia. ${ }^{12}$

As reflexões contidas nesse texto partiram das vivências propiciadas pelo curso de extensão Iniciação em Educação Musical e Escuta Sensível, coordenado por nós e

\footnotetext{
${ }^{11}$ Antes de me tornar professora da Universidade Federal Fluminense, atuei como instrumentista, professora de música em escolas técnicas e realizei outros trabalhos na área da performance musical. Minha graduação foi em licenciatura em Educação Artística, com habilitação em Música, e o mestrado em Música, ambos os cursos realizados na UNIRIO. Meu doutorado foi realizado no Programa de PósGraduação em Educação da UFF. A professora Silmara Lídia Marton é da área da filosofia, atua na formação de pedagogos e desenvolveu uma Tese de Doutorado em Educação na UFRN intitulada Paisagens sonoras, tempos e autoformação (2008) e uma Dissertação de Mestrado (2005) na mesma instituição com o título Música, filosofia e formação: por uma escuta sensível do mundo.

${ }^{12}$ Paisagens sonoras é a tradução do neologismo soundscape, criado pelo músico Raymond Murray Schafer para se referir a todo campo acústico, como uma música, um som natural ou outro artificialmente produzido pela cultura. Mediante suas pesquisas, o estudioso verificou que a paisagem sonora do mundo evoluiu historicamente e isso afetou proporcionalmente o comportamento humano. Argumenta que a tecnologia, à medida que se diversificou, ampliou e desenvolveu, trouxe consigo a superpovoação de sons do mundo e sua homogeneização e, em consequência, o domínio e o monopólio de certa paisagem sonora, ocultando e diminuindo a variedade de outros sons que são justamente as "espécies em extinção" na contemporaneidade, em sua maioria, os sons da natureza. O autor enfatiza, então, a necessidade de proteção desses sons e de nossa clariaudiência - a audição clara -, e não o ensurdecimento.
} 
realizado entre agosto e dezembro de 2010. O curso contou com uma turma bastante heterogênea, composta por professores da rede pública de Angra dos Reis e de Mangaratiba, por estudantes do curso de pedagogia do IEAR e por alguns profissionais da área musical da cidade de Angra dos Reis. Concluímos afirmando que a música

mais do que servir para uma exigência legal, deve ser ensinada porque, de fato, potencializa os aspectos sensíveis da condição humana, estimulando uma formação mais plena. A educação musical pode ser um campo aberto e poroso de possibilidades de criação, de novas percepções de mundo, significações e sentidos para a vida. (REQUIÃO; MARTON, 2011, p. 846)

\section{Sons e pulso: reflexões e percurso de um projeto de pesquisa e extensão}

No trabalho apresentado no XXI Congresso Nacional da Associação Brasileira de Educação Musical, que teve sede na cidade de Pirenópolis em novembro de 2013, discutimos o percurso realizado por meio de projetos de pesquisa e extensão na busca por subsídios que pudessem nos ajudar a desenvolver propostas de uma formação inicial e continuada na área da educação musical para professores não especialistas em música (REQUIÃO, 2013a). De forma sucinta, descrevemos o percurso transcorrido entre julho de 2011 e dezembro de 2012, quando buscamos conhecer as práticas musicais nas escolas públicas municipais de Angra dos Reis, de Mangaratiba, de Paraty e de Rio Claro. Mostramos ainda o desenvolvimento de um curso de extensão destinado a professores da rede pública de Mangaratiba que resultou na publicação do material didático audiovisual intitulado Sons e pulso: formação inicial em música e educação (REQUIÃO, 2013b).

$\mathrm{Na}$ organização do livro a nossa proposta foi apresentar um conteúdo específico através de uma demonstração audiovisual (CD e ilustrações) conduzida através de um narrador. Seus capítulos foram estruturados em três partes: apresentação audiovisual dos conteúdos, exercícios e indicação de possíveis desdobramentos e possibilidades para 0 desenvolvimento de outras atividades para o trabalho em sala de aula. Ao final, há uma indicação bibliográfica básica da área da música. No livro/CD trabalhamos exclusivamente com os parâmetros musicais (altura, duração, timbre e intensidade) e com as noções de pulso e andamento. Nossa intenção foi a de oferecer subsídios aos professores não especializados para que pudessem trabalhar a música nas escolas a partir de uma formação inicial no qual o trabalho com elementos básicos 
da música através da habilidade de perceber e manipular esses sons seja improvisando, compondo ou executando determinada sequência musical - fosse motivador. (REQUIÃO, 2013a, p. 2293-2294)

O material foi distribuído a cerca de 700 professores da Educação Infantil em encontros promovidos em parceria com a SME de cada município. Esse trabalho nos proporcionou a compreensão de que precisamos conhecer in loco a realidade das escolas, se quisermos efetivamente contribuir com as suas demandas, não apenas visando atendê-las, mas também discuti-las. Nesse sentido, a parceria universidade/escola nos pareceu um caminho importante. Compreendemos ainda que o papel do professorpedagogo não é o de substituir o professor especialista, mas, ao contrário disso, é dessa parceria que poderão frutificar experiências enriquecedoras no ambiente escolar. E o mais importante foi perceber que os professores se sentiram à vontade no trabalho com a música e puderam realizar atividades que, apesar de muito simples, se tornaram uma fonte de motivação para o trabalho com a música em sala de aula.

\section{Apenas a lei não basta: o processo de implementação da educação musical em um curso de pedagogia do Litoral Sul Fluminense}

No ano de 2015, por ocasião do XXII Congresso da Associação Brasileira de Educação Musical, evento realizado na cidade de Natal (RN), discutimos o processo que culminou na implementação da educação musical como um componente curricular obrigatório do curso de Pedagogia do IEAR (REQUIÃO, 2015a). Argumentamos que, a despeito da Lei 11.769, o reconhecimento da Educação Musical como uma disciplina essencial à formação do pedagogo necessita de processos que levem à sua legitimação perante a comunidade acadêmica. Resgatamos o contexto no qual se deram esses processos iniciados em 2009 e que culminaram, em 2015, com a primeira turma que teve a Educação Musical como uma disciplina obrigatória no curso de Pedagogia do IEAR.

Conforme indica o título do artigo, argumentamos que apenas a prescrição imposta por leis como a 11.769 não basta, tendo sido também necessário um percurso que incluísse ações de ensino, de pesquisa e de extensão para que obtivéssemos o reconhecimento que tornou possível a inclusão da disciplina em um currículo que, naquela ocasião, estava sendo reduzido de nove para oito períodos de duração. 
Destacamos a nossa experiência com disciplinas optativas em Educação Musical, em cursos de extensão oferecidos aos estudantes e aos professores da rede pública da região e em três projetos de pesquisa aprovados na FAPERJ, o que nos possibilitou oferecer bolsas de iniciação científica e de treinamento e capacitação técnica aos nossos estudantes. Contamos também com bolsas oferecidas pela UFF que foram muito importantes por possibilitarem uma maior participação de estudantes no projeto. ${ }^{13}$

Como reflexo disso, houve um incremento do interesse de alunos da pedagogia em desenvolverem os seus Trabalhos de Conclusão de Curso por meio de temáticas voltadas para o ensino de música na escola. Considero muito importante esse ponto, pois proporcionou um maior envolvimento dos estudantes de pedagogia com as questões que permeiam as discussões na área da educação musical. ${ }^{14}$

No artigo, destacamos um trecho do documento produzido pelo Conselho Nacional de Educação que observa a escassez de professores habilitados para o ensino de música no âmbito escolar e a necessidade de uma formação inicial e continuada para os professores em exercício. No documento se lê que

os cursos de Pedagogia devem incluir em seus desenhos curriculares conteúdos relacionados ao ensino de música para a docência na Educação Infantil e nos anos iniciais do Ensino Fundamental. Nesse sentido ainda, os cursos de formação continuada, visando uma melhor qualificação pedagógica para o ensino de música, precisam promover o aprofundamento dos saberes e experiências adquiridos na formação inicial e na prática docente, bem como promover a produção de novos saberes que concebam a música como instrumento pedagógico. (BRASIL, 2013) $)^{15}$

\footnotetext{
${ }^{13}$ Bolsa de Extensão (PROEX/UFF) e Bolsa de Desenvolvimento Acadêmico (PROGRAD/UFF).

${ }^{14}$ São eles: Os desafios da arte frente às dificuldades do aprender, de Adryan Nunweiler Reis Maciel (MACIEL, 2018); Entendendo a arte na educação infantil: uma reflexão sobre minha formação como pedagoga, de Maria Cleusa Pereira Bernardo (BERNARDO, 2017); Educação musical e a formação do pedagogo: reflexões sobre uma experiência formativa, de Giselli Fabiane da Silva Gomes (GOMES, 2017); Música na escola: buscando nas paisagens sonoras novas perspectivas de ensino e aprendizagem, de Damáris Fontes de Queiroga Paulo (PAULO, 2016); Letras de música: reflexões sobre a aprendizagem significativa a partir da análise da produção textual discente no Ensino Médio, de Renata Emily Fonseca Rodrigues (RODRIGUES, 2015); A importância da educação musical na formação do pedagogo: implicações da lei 11.769, de Fernanda Luiza dos Santos Costa (COSTA, 2015); e Aprendendo música na creche: um relato de experiência, de Marta Cruz do Nascimento Almeida (ALMEIDA, 2012).
}

${ }^{15} \mathrm{Na}$ ocasião, o documento ainda não havia sido homologado. 
Como conclusão, observamos que

a articulação entre ações de ensino, pesquisa e extensão associadas a dispositivos legais foi o que proporcionou o reconhecimento pela comunidade acadêmica da educação musical como um elemento fundamental para a formação inicial de pedagogos e para a formação continuada dos professores da rede pública. Desta forma, entendendo a importância em articular o ensino, a pesquisa e a extensão, esperamos contribuir com o conhecimento da área e com a formação inicial e continuada de professores, em especial os que atuam na educação infantil e nas séries iniciais da educação básica. (REQUIÃO, 2015a, s. p.)

\section{Educação musical a distância: uma alternativa na formação inicial de professores não especialistas na área da música}

No mesmo evento citado acima, apresentamos uma comunicação de pesquisa que trata da avaliação realizada sobre o material didático audiovisual - Sons e pulso: formação inicial em música e educação (REQUIÃO, 2013b) - e o seu desdobramento em um curso a distância através da plataforma moodle (REQUIÃO, 2015b). Se o primeiro apoiou-se em um CD que traduzia em sons o texto e as ilustrações contidas no livro, de forma que "o texto nele escrito é 'falado' por uma narradora e toda ilustração gráfica tem a sua representação sonora" (idem, s. p.), o curso naquela plataforma pretendeu possibilitar que as representações gráficas tivessem movimento, buscando uma melhor articulação entre o som e a imagem. Nas duas situações, o lido/visto e o escutado devem se dar de forma simultânea.

Destacamos também que os dois materiais são possibilidades de aprendizagem sem a presença de um mediador/professor. A avaliação do material físico, realizada por meio de um questionário enviado aos professores que receberam o material, nos mostrou ser viável o desenvolvimento e a aplicação de propostas de ensino de forma não presencial. Os dados nos indicaram que pode ser positiva a experiência de uma autoformação, ao menos como uma alavanca inicial que motive a busca por novos meios de aprendizagem. O contexto no qual desenvolvemos o nosso trabalho - considerando a abrangência dessa região litorânea que conta também com muitas ilhas - foi outro fator que nos motivou na adaptação do material físico em material digital. 
A possibilidade de adaptar o conteúdo desse material didático para um curso na modalidade EaD online é a oportunidade para atender a uma demanda impossível de ser abarcada em sua totalidade de forma presencial. Por outro lado, através de uma plataforma online, é possível apresentar de forma "animada" o material que antes era audiovisual, porém estático. Outra grande vantagem do curso, em relação ao material impresso, é a possibilidade de adaptação do conteúdo no decorrer do próprio curso. A interatividade através de chats - em tempo real -, e dos fóruns de discussão - que propiciam a interação entre os estudantes - é de fundamental importância para um melhor aproveitamento do curso. (REQUIÃO, 2015b, s. p.)

O curso a distância teve uma turma-piloto no segundo semestre de 2014, sendo oferecida no curso de Pedagogia como uma disciplina optativa no primeiro semestre de 2015.

Essa breve experiência que tivemos foi extremamente positiva. Na avaliação do curso realizada pelas turmas do primeiro semestre de 2015 tivemos respostas como: "um bom formato de fácil compreensão"; "achei uma linguagem simples e esclarecedora"; "a linguagem é bem clara e os recursos também"; "bem colocados, falados pausadamente para uma melhor compreensão, e os recursos em áudio e vídeo ajudaram muito"; "achei a plataforma bem clara, desde a apresentação e a explicação sobre os temas até os exercícios [...] e a linguagem utilizada de fácil entendimento"; "uma dinâmica leve pra quem tem uma rotina e um trabalho iguais aos que tenho". (REQUIÃO, 2015b, s. p.)

Como conclusão, observamos ser a educação musical a distância uma possibilidade viável para a formação inicial de professores não especialistas na área da música.

\section{Estudos subsequentes e considerações sobre a música}

Os trabalhos acima refletem o percurso traçado nesses últimos anos desde o meu ingresso como docente no Instituto de Educação de Angra dos Reis. Os estudos subsequentes aos apresentados acima retratam, da mesma forma, uma busca incessante pela compreensão do lugar da música no processo de formação da criança no espaço escolar e, como consequência, sobre a formação musical desejável ao professorpedagogo para atuar na educação infantil e nas séries iniciais do ensino fundamental. Nesse contexto, entendemos que uma concepção de educação musical a partir do 
trabalho do professor regente deve preservar o compromisso com a formação integral da criança. A educação musical na escola teria, então, o propósito de propiciar possibilidades de ampliação na relação que essas pessoas (adultos e crianças) estabeleceram em seu meio com a música.

O primeiro desses estudos, ainda em andamento, busca observar a relação entre o pedagogo em formação e os materiais didáticos na área da música destinados ao professor não especialista. Estão previstas etapas, já em andamento, de levantamento bibliográfico, para selecionar artigos sobre a temática Música e Educação, que envolvam a questão do material didático no ensino de música na educação básica, ${ }^{16}$ e materiais didáticos publicados a partir do ano de 2008, quando foi promulgada a Lei 11.769, destinados ao professor não especialista. Vimos realizando estudos sobre a utilização desse material didático por estudantes de pedagogia, observando o que chamamos de legibilidade, ou seja, a forma pela qual eles apreendem este último. É importante salientar que o nosso objetivo não é o de julgar a pertinência ou não das atividades propostas nos materiais, mas sim o de analisar a forma como os estudantes interpretam, executam e adaptam tais atividades. Nossa hipótese inicial é a de que grande parte desse material não é acessível a esse professor não especialista, sendo, em função disso, necessária a mediação de um professor com formação específica na área da música. A etapa final do projeto prevê o desenvolvimento de um livro com atividades musicais criadas ou adaptadas pelos estudantes de pedagogia do IEAR.

Em outro estudo, também em andamento, nos interessa conhecer e compreender o trabalho que vem sendo desenvolvido nas escolas de educação básica por nossos alunos egressos que tiveram a oportunidade de participar das ações relatadas no decorrer deste artigo. Promovemos uma conversa com cinco ex-alunos do curso de Pedagogia do IEAR que relataram questões que, em geral, não são consideradas nas discussões sobre a música na escola. Um ponto surpreendente foi saber da contratação de duas dessas alunas como professoras de música em uma escola particular da região de Angra dos Reis: "Fui trabalhar nessa escola como professora de música a convite da coordenadora que foi aluna aqui também. Por saber que a gente trabalhava em um

\footnotetext{
16 Trata-se de uma abordagem quantitativa elaborada a partir do modelo de mineração de fontes bibliográficas proposto por Costa (2010). As buscas serão realizadas nas bases de dados Scopus, SciELO e Web of science, por meio do Portal Periódicos CAPES.
} 
projeto de música, ela convidou a mim e a Natália. Nunca imaginei que eu daria aula só de música". ${ }^{17}$

Além das questões que já foram exaustivamente apresentadas por pesquisadores sobre a pouca relevância que a arte assume nos currículos escolares diante de outras disciplinas e, particularmente, no que tange ao ensino de música na educação básica e à associação das atividades musicais a momentos festivos ou recreativos, ${ }^{18}$ os alunos egressos enfatizaram que a vivência que tiveram com as artes, e com a música em particular, entra diretamente em conflito com a realidade da escola:

Essa atividade com música tem que gerar alguma coisa, uma dobradura, um desenho, uma pintura para, no final do semestre, entregar aos pais. A professora sai de sala e, às vezes, duas turmas são juntadas. Eu ganho por hora. Então, quando juntam as turmas acaba que ganho menos. As questões que discutimos na graduação sobre educação musical passam longe da escola. A diretora ainda disse que eu poderia juntar três turmas porque a aula era de música, ou seja, não tinha nada para aprender. ${ }^{19}$

O que eles relatam parece ser, na verdade, consequência de toda uma situação que desvaloriza e descaracteriza os processos de produção artísticos, um sentimento de impotência diante das restrições que têm para o trabalho com a arte na escola. Outra aluna egressa relata: "A diretora até achou bom eu ter no meu currículo o projeto de música. De vez em quando, ela vem com alguma ideia sobre isso, mas é sempre meio absurdo. Porque lá cada um faz o que quer, não havendo nenhum tipo de planejamento coletivo". ${ }^{20}$ Tal situação nos revela que, não obstante a formação que tiveram na área da educação musical, a sua prática docente é limitada pela compreensão (ou pela falta dela), que se tem no âmbito escolar, do lugar da música nos processos de formação humana.

No sentido contrário, conforme já mencionado, nos documentos que orientam a educação no Brasil, como os Parâmetros Curriculares Nacionais (BRASIL, 1997), a cultura ocupa lugar de destaque. O texto do PCN ressalta que a "arte tem uma função tão importante quanto a dos outros conhecimentos no processo de ensino e aprendizagem"

\footnotetext{
${ }^{17}$ Aluna egressa do curso de Pedagogia do IEAR em conversa realizada em 19 de dezembro de 2016.

${ }^{18}$ Vimos nos últimos anos discutindo essa questão, sendo a mais recente encontrada em Requião (2017).

${ }^{19}$ Idem.

${ }^{20}$ Idem.
} 
(1997, p. 20) e que "o conhecimento da arte abre perspectivas para que o aluno tenha uma compreensão do mundo na qual a dimensão poética esteja presente: a arte ensina que é possível transformar continuamente a existência" (idem).

Não obstante as questões defendidas acima, o PCN já em 1997, data de sua publicação, reconhece um outro cenário para as artes nas escolas brasileiras, coisa que perdura nos dias de hoje, conforme as pesquisas citadas:

O que se observa, então, é uma espécie de círculo vicioso no qual um sistema extremamente precário de formação reforça o espaço pouco definido da área com relação às outras disciplinas do currículo escolar. Sem uma consciência clara de sua função e sem uma fundamentação consistente de arte como área de conhecimento com conteúdos específicos, os professores não conseguem formular um quadro de referências conceituais e metodológicas para alicerçar sua ação pedagógica; não há material adequado para as aulas práticas, nem material didático de qualidade para dar suporte às aulas teóricas. (BRASIL, 1997, p. 26)

Impõe-se a necessidade de se compreender as motivações sobre a ineficiência ou a inexistência do ensino de artes nas escolas brasileiras, além da pouca ou nenhuma presença dessa área nos cursos de licenciatura em Pedagogia. Nesse sentido, nos cabe perguntar se tal cenário é fruto de uma inoperância estatal ou se seria, ao mesmo tempo, parte e consequência de políticas públicas voltadas, por um lado, para a educação brasileira, e pelo outro, para a cultura.

Em outras ocasiões, nos dedicamos a investigar o sentido que a cultura passou a ter para as políticas públicas no Brasil a partir do início dos anos 2000 (REQUIÃO, 2009, 2013 e 2016). Foram observados, em particular, os rumos tomados em decorrência do desmembramento do Ministério da Educação e Cultura ocorrido em 1985, quando o Ministério da Cultura (MinC) teve como principal argumento para a sua criação a “necessidade de métodos, técnicas e instrumentos diversificados de reflexão e administração" que se justificaria pela exigência de "políticas específicas bem caracterizadas, a reclamarem o desmembramento da atual estrutura unitária em dois ministérios autônomos" (BRASIL, 1985). Nesse ínterim, o MinC desenvolveu uma série de ações publicadas no relatório final do projeto de Desenvolvimento do Programa Nacional de Economia da Cultura (BRASIL, 2016). No relatório, foi revelada a promissora 
capacidade de desenvolvimento e expansão do que viria se tornar hoje a chamada indústria criativa.

\begin{abstract}
Atualmente, já é notável a importância dos processos econômicos engendrados a partir de organizações e agentes culturais e criativos, apesar de alguns processos de parametrização de análise do impacto econômico ainda precisarem ser amadurecidos. As pesquisas que se aproximam da mensuração desse ambiente já conseguem materializar algumas dessas importantes perspectivas, como os setores econômicos culturais contribuírem significativamente para a produção de riqueza nacional, constituírem uma parte considerável da cesta de exportação brasileira e mobilizarem um mercado interno de bilhões de dólares. Também se destaca que os segmentos culturais representam parte significativa da malha empresarial brasileira, com alta densidade de micro empreendimentos, e do total de ocupações formais. Dessa forma, tanto em análise macro quanto microeconômica, compreende-se a importância dos setores culturais na diversificação da economia brasileira, apoiando a reversão da especialização regressiva, a inclusão produtiva e o aquecimento do mercado interno. Hoje chegamos ao posicionamento da cultura enquanto vetor, contexto e finalidade do desenvolvimento, do território como principal plataforma de organização e intervenção do processo de desenvolvimento e da diversidade cultural como o principal ativo a ser expresso, refletido e valorizado nessas estratégias. (BRASIL, 2016, p. 4)
\end{abstract}

A arte transformada em mercadoria representa um processo de produção interessado, ou seja, que precisa responder a mecanismos da economia capitalista de geração de lucro, sendo o seu processo de produção impulsionado por seu valor de troca. Nesse caminho, distancia-se a produção artística de seu valor de uso, cabendo ao MinC ocupar-se da cultura enquanto um setor da economia, desconsiderando até certo ponto os processos de produção cultural de caráter desinteressado, não produtivo ao capital, de caráter formativo. Cito aqui David Harvey que, de forma muito apropriada, destaca o caráter diferenciado que as mercadorias culturais podem assumir.

É inegável que a cultura se transformou em algum gênero de mercadoria. No entanto, também há a crença muito difundida de que algo muito especial envolve os produtos e os eventos culturais [...] sendo preciso pôlos à parte das mercadorias normais, como camisas e sapatos. Talvez façamos isso porque somente conseguimos pensar a seu respeito como produtos e eventos que estão num plano mais elevado da criatividade e do sentido humano, diferente do plano das fábricas de produção de massa e do consumo de massa. (HARVEY, 2005, p. 221) 
Esse ponto é de especial interesse ao nosso debate. O fetiche que envolve os produtos culturais envolve também o seu processo de produção e os seus produtores. Não são raros os discursos de artistas e do senso comum que enfatizam as ideias de dom e de talento como algo necessário, desejável e intrínseco à atividade artística. Associando as noções de dom e de talento à ideia da arte como ócio ou lazer (concepção que frequentemente encontramos na escola), temos um processo de mistificação da produção musical que ofusca tanto as relações de trabalho que nela se estabelecem quanto a própria formação musical (REQUIÃO, 2010).

\begin{abstract}
A associação conceitual que o senso comum faz do trabalho artístico com o lazer, com o entretenimento e com o ócio se estende ao sujeito que usufrui e, principalmente, segundo essa visão, a quem produz. É sabido que tal conceito de atividade artística como não produtiva (ou que não gera renda) apenas reforça a ideia do senso comum de que o trabalho de arte se funda numa espécie de inspiração divina, de um talento individual ou um dom, velando a sua materialidade concreta e alimentando a dissociação entre o trabalho de arte e o trabalho em geral. (REIS; REQUIÃO, 2013, p. 37)
\end{abstract}

Reis (2004) observa que mesmo o PCN apresenta uma imagem deturpada dos processos de produção artísticos, contribuindo assim para o empobrecimento de seu conteúdo nos currículos escolares: “evidencia-se no documento a visão de que a práxis artística é um dado natural, o que reforça a mistificação, em torno do processo da criação artística, do ato criador, da figura do gênio" (REIS, 2004, p. 245). Como consequência desse processo, não poderia deixar de citar a recém-criada Base Nacional Comum Curricular (BNCC) que vem sendo criticada pelo esvaziamento que poderá proporcionar ao conhecimento artístico. Segundo Peres (2017, p. 24), por exemplo, "a BNCC enfraquece a posição da arte no currículo escolar, configurando-se como um retrocesso de todas as conquistas desse campo disciplinar". ${ }^{21}$

Por fim, são esses os caminhos que venho encontrando para discutir e compreender a minha prática pedagógica, experiências que buscam uma maior compreensão sobre o papel da arte na educação infantil e nas séries iniciais do ensino fundamental, área de atuação do professor-pedagogo, e como a formação acadêmica e a

\footnotetext{
${ }^{21}$ As questões que permeiam as discussões sobre a BNCC, por serem demasiadamente complexas, não serão tratadas nesse texto.
} 
atuação desse professor podem favorecer o desenvolvimento da arte nesse âmbito escolar. De acordo com Santos (2012, p. 266), vimos refletindo sobre essa experiência compreendendo a arte - e a música em particular - como uma forma de conhecimento, de expressão e de pensamento fundamental para a formação e o trabalho do pedagogo. De outro modo, mas no mesmo sentido, observamos a necessidade de que é preciso não desvincular da discussão em torno da presença da música na escola questões relativas à gestão escolar, à formação de professores (inicial e continuada), às políticas públicas (inclusive aquelas voltadas para a cultura), à relação entre o professor regente de turma e professor especialista, à polivalência em artes (e à politecnia como uma outra forma de encarar as diversas linguagens na área das artes), à interdisciplinaridade e outras que inevitavelmente estão articuladas e que não caberiam nos limites deste artigo.

Como referência ao artigo de Jorge Larrosa Bondía (2002), buscamos na experiência - eu e meus parceiros - uma inspiração para refletirmos sobre a nossa prática. Percebemos que, de alguma forma, estávamos, no início desse percurso, disponíveis para que, através de uma escuta atenta e sensível, pudéssemos desenhar um caminho que envolveu idas e vindas, escutas e silêncios, ações e reações. Essa experiência nos atravessou e ainda nos atravessa. Ao reler o presente texto e buscar uma forma de finalizá-lo, confesso a impossibilidade de narrar essa história usando apenas palavras. 0 saber dessa experiência talvez seja melhor encontrado em suas entrelinhas. 
ALMEIDA, Marta Cruz do Nascimento. Aprendendo música na creche: um relato de experiência. 2012. (Trabalho de Conclusão de Curso) - IEAR, Angra dos Reis, 2012.

BELLOCHIO, Cláudia Ribeiro; WEBER, Vanessa; e SOUZA, Zelmielen Adornes de. Música e unidocência: pensando a formação e as práticas de professores de referência. Revista da FAEEBA - Educação e Contemporaneidade, Salvador, v. 26, n. 48, p. 205-22, jan./abr., 2017. Disponível em:

<https://www.revistas.uneb.br/index.php/faeeba/article/view/3587/2300>. Acesso em: 05 mai. 2017.

BERNARDO, Maria Cleusa Pereira. Entendendo a arte na educação infantil: uma reflexão sobre minha formação como pedagoga. (Trabalho de conclusão de curso) - IEAR, Angra dos Reis, 2017.

BONDÍA, Jorge Larrosa. Notas sobre a experiência e o saber da experiência. Revista Brasileira de Educação, n. 19, jan./abr., p. 20-28, 2002. Disponível em: <http://www.scielo.br/pdf/rbedu/n19/n19a02.pdf>. Acesso em: 21 set. 2017.

BRASIL. Casa Civil. Decreto n 91.144, de 15 de março de 1985. Cria o Ministério da Cultura e dispõe sobre a estrutura, transferindo-lhe os órgãos que menciona, e dá outras providências. 1985. Disponível em: <http://portal.mec.gov.br/arquivos/pdf/d91144.pdf>. Acesso em: 11 dez. 2011.

BRASIL. Conselho Nacional de Educação. Diretrizes nacionais para a operacionalização do ensino de música na educação básica: Parecer CNE/CEB n. 12/2013. Disponível em: <http://portal.mec.gov.br>. Acesso em: 11 fev. 2016.

BRASIL. Desenvolvimento do Programa Nacional de Economia da Cultura. Relatório final. Projeto MinC-UNESCO 914BRZ4013. Intersetorialidade, Descentralização e Acesso à Cultura no Brasil, maio 2016. Disponível em:

<http://www.cultura.gov.br/documents/10883/1337477/PROGRAMA+NACIONAL+DE+ECO NOMIA+DA+CULTURA_PNEC_RELAT\%C3\%93RIO+FINAL.compressed.pdf/8b6dec76-9a6c4992-acaf-b11ezeg4e6a6>. Acesso em: 30 jun. 2018.

BRASIL. Lei $n^{\circ}$ 9.394, de 20 de dezembro de 1996. Estabelece as diretrizes e bases da educação nacional. Diário Oficial da União, Seção 1, p. 27833, 23/12/1996. Disponível em: http://www.planalto.gov.br/ccivil_03/Leis/L9394.htm. Acesso em: 12 mai. 2017.

BRASIL. Lei n ${ }^{\circ}$ 5.692, de 11 de agosto de 1971. Fixa Diretrizes e Bases para o ensino de $1^{\circ} \mathrm{e}$ $2^{\circ}$ graus, e dá outras providências. Diário Oficial da União, Seção 1, p. 637, 712/8/1971. Disponível em: <http://www2.camara.leg.br/legin/fed/lei/1970-1979/lei-5692-11-agosto-1971357752-publicacaooriginal-1-pl.html>. Acesso em: 16 set. 2017.

BRASIL. Lei $n^{\circ} 13.278$, de 2 de maio de 2016. Altera o § 60 do art. 26 da Lei no 9.394, de 20 de dezembro de 1996, que fixa as diretrizes e bases da educação nacional, referente ao 
ensino da arte. Diário Oficial da União, Brasília, seção 1, p. 1, 3 maio 2016. Disponível em: <http://www.planalto.gov.br/ccivil_03/_at02015-2018/2016/lei/l13278.htm>. Acesso em: 28 fev. 2018.

BRASIL. Lei $n^{\circ} 11.769$, de 18 de agosto de 2008. Altera a Lei $n^{\circ} 9.394$, de 20 de dezembro de 1996 para dispor sobre a obrigatoriedade do ensino da música na educação básica. Diário Oficial da União, Brasília, ano CXLV, n. 159, seção 1, p. 1, 19 ago. 2008. . Disponível em: <http://www2.camara.leg.br/legin/fed/lei/2008/lei-11769-18-agosto-2008-579455publicacaooriginal-102349-pl.html>. Acesso em: 28 fev. 2018.

BRASIL. Ministério da Educação. Resolução CNE/CP, n. 1, de 15 de maio de 2006. Institui Diretrizes Curriculares Nacionais para o Curso de Graduação em Pedagogia, licenciatura. Brasília, DF, 2006. Disponível em: <http://portal.mec.gov.br/cne/arquivos /pdf/rcp01_06.pdf>. Acesso em: 01 mar. 2018.

BRASIL. Ministério da Educação e do Desporto. Secretaria de Educação Fundamental. Referencial curricular nacional para a educação infantil. Brasília: MEC/SEF, 1998.

BRASIL. Secretaria de Educação Fundamental. Parâmetros curriculares nacionais: arte. Brasília: MEC/SEF, 1997.

COSTA, Fernanda Luiza dos Santos. A importância da educação musical na formação do pedagogo: implicações da lei 11.769/08. 2015. (Trabalho de conclusão de curso) - IEAR, Angra dos Reis, 2015.

COSTA, Helder Gomes. Modelo para webibliomining: proposta e caso de aplicação.

Revista da FAE, v. 13, n. 1, p. 115-126. 2010. Disponível em:

<http://www.unifae.br/publicacoes/v.13_01-2010.pdf>. Acesso em: 17 jul. 2013.

FIGUEIREDO, Sérgio Luiz Ferreira. A música e as artes na formação do pedagogo: polivalência ou interdisciplinaridade. Revista da FAEEBA - Educação e

Contemporaneidade, Salvador, v. 26, n. 48, p. 79-96, jan./abr., 2017. Disponível em: <https://www.revistas.uneb.br/index.php/ faeeba/article/view/3579/2292>. Acesso em: 05 mai. 2017.

FIGUEIREDO, Sérgio Luiz Ferreira. A preparação musical de professores generalistas no Brasil. Revista da ABEM, Porto Alegre, v. 11, p. 55-61, 2004.

FONTERRADA, Marisa Trench de Oliveira. De tramas e fios: um ensaio sobre música e educação. São Paulo: UNESP; Rio de Janeiro: FUNARTE, 2008.

GOMES, Giselli Fabiane da Silva. Educação musical e a formação do pedagogo: reflexões sobre uma experiência formativa. (Trabalho de conclusão de curso) - IEAR, Angra dos Reis, 2017.

HARVEY, David. A produção capitalista do espaço. São Paulo: Annablume, 2005. 
MACIEL, Adryan Nunweiler Reis. Os desafios da arte frente às dificuldades do aprender. 2018 (Trabalho de conclusão de curso) - IEAR, Angra dos Reis, 2018.

PAULO, Damáris Fontes de Queiroga. Música na escola: buscando nas paisagens sonoras novas perspectivas de ensino e aprendizagem. 2016. (Trabalho de conclusão de curso) IEAR, Angra dos Reis, 2016.

PERES, José Roberto Pereira. Questões atuais do ensino de arte no Brasil: o lugar da arte na base nacional comum curricular. Revista de Educação, Desenho e Artes Visuais, Rio de Janeiro: Colégio Pedro II, v. 1, n. 1, p. 24-36, 2017.

REIS, Ronaldo Rosas. Trabalho e conhecimento estético. Trabalho, Educação e Saúde, v. 2 n. 2, p. 227-250, 2004.

REIS, Ronaldo Rosas; REQUIÃO, Luciana. Arte e formação humana: estatuto ontológico e sistema de arte. Conhecimento \& Diversidade, Niterói, n. 9, p. 37-47, jan./jun., 2013.

REQUIÃO, Luciana. A educação musical em sala de aula e a música na formação do professor unidocente: uma experiência com estudantes de pedagogia do Instituto de Educação de Angra dos Reis. In: RIBEIRO, William de Goes. Práticas pedagógicas, currículo e formação docente: tecendo reflexões em educação. Curitiba: CRV, p. 101-113, 2017.

REQUIÃO, Luciana. Apenas a lei não basta: o processo de implementação da educação musical em um curso de pedagogia do Litoral Sul Fluminense. In: CONGRESSO NACIONAL DA ASSOCIAÇÃO BRASILEIRA DE EDUCAÇÃO MUSICAL, XXII, 2015, Natal. Anais... Natal: ABEM, 2015a. Disponível em:

<http://abemeducacaomusical.com.br/conferencias/index.php/

xxiicongresso/xxiicongresso/paper/viewFile/1191/486>. Acesso em: 19 fev. 2016.

REQUIÃO, Luciana. Educação musical a distância: uma alternativa na formação inicial de professores não especialistas na área da música. In: CONGRESSO NACIONAL DA ASSOCIAÇÃO BRASILEIRA DE EDUCAÇÃO MUSICAL, XXII, 2015, Natal. Anais... Natal: ABEM, 2015b. Disponível em: <http://abemeducacaomusical.com.br/conferencias/index.php/ xxiicongresso/ xxiicongresso/paper/viewFile/1191/486>. Acesso em: 19 fev. 2016.

REQUIÃO, Luciana. Eis aí a Lapa...: processos e relações de trabalho do músico nas casas de shows da Lapa. São Paulo: Annablume, 2010.

REQUIÃO, Luciana. “Festa acabada, músicos a pé!”: um estudo crítico sobre as relações de trabalho de músicos atuantes no estado do Rio de Janeiro. Revista do Instituto de Estudos Brasileiros, v. 64, p. 249-274, 2016.

REQUIÃO, Luciana. Música nas escolas: mercadoria ou formação humana? Educação. Rio Claro, v. 23, n. 43, p. 169-181, 2013. 
REQUIÃO, Luciana. O valor econômico da cultura: um debate sobre formas de apropriação do conceito de cultura. Cadernos Cemarx, v. 6, p. 153-168, 2009.

REQUIÃO, Luciana. Sons e pulso: formação inicial em música e educação. Rio de Janeiro: Edição do autor, 2013b.

REQUIÃO, Luciana. Sons e pulso: reflexões e percurso de um projeto de pesquisa e extensão. In: CONGRESSO NACIONAL DA ASSOCIAÇÃO BRASILEIRA DE EDUCAÇÃO MUSICAL, XXI, 2013a, Pirenópolis. Anais... Pirenópolis: ABEM, 2013C. Disponível em: <http://abemeducacaomusical.com.br/sistemas/anais/congressos/ABEM_2013_p.pdf>. Acesso em: 16 set. 2017 .

REQUIÃO, Luciana; MARTON, Silmara Lidia. Educação musical e escuta sensível: uma proposta de formação de professores. In: CONGRESSO NACIONAL DA ASSOCIAÇÃO BRASILEIRA DE EDUCAÇÃO MUSICAL, XX, 2011. Vitória. Anais... Vitória: ABEM, 2011.

RODRIGUES, Renata Emily Fonseca. Letras de música: reflexões sobre a aprendizagem significativa a partir da análise da produção textual discente no ensino médio. 2015. (Trabalho de conclusão de curso) - IEAR, Angra dos Reis, 2015.

SANTOS, Regina Márcia Simão. Relações entre educação e ensino a partir do campo do currículo: o caso da música. In: $35^{\text {a }}$ REUNIÃO ANUAL DA ANPED, 2012, Porto de Galinhas. GT de Currículo - ANPEd. Anais... Campinas: UNICAMP, 2012. Disponível em: https://www.fe.unicamp.br/gtcurriculoanped/35RA/trabalhos/TE-Anped2012campo_do_currlculo_m\%fasica.pdf. Acesso em: 21 set. 2017.

SANTOS, Regina Márcia Simão. Um paradigma estético para o currículo. In: SANTOS, Regina Márcia Simão. (Org). Música, cultura e educação: os múltiplos espaços de educação musical. Porto Alegre: Sulina, 2012, p. 251-292.

SCHAFER, Raymond Murray. A afinação do mundo: uma exploração pioneira pela história passada e pelo atual estado do mais negligenciado aspecto do nosso ambiente: a paisagem sonora. São Paulo: Editora UNESP, 2001.

SEKEFF, Maria de Lourdes. Da música: seus usos e recursos. São Paulo: Editora UNESP, 2002. 